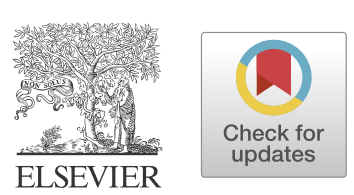

CJC Open 3 (2021) 1238-1248

\title{
Review
}

\section{The Effect of Testosterone on Cardiovascular Disease and Cardiovascular Risk Factors in Men: A Review of Clinical and Preclinical Data}

\author{
Hargun Kaur, ${ }^{a}$ and Geoff H. Werstuck, $\mathrm{PhD}^{\mathrm{b}, \mathrm{c}}$ \\ ${ }^{a}$ Faculty of Health Sciences, McMaster University, Hamilton, Ontario, Canada \\ ${ }^{b}$ Thrombosis and Atherosclerosis Research Institute, McMaster University, Hamilton, Ontario, Canada \\ ${ }^{c}$ Department of Medicine, McMaster University, Hamilton, Ontario, Canada
}

\begin{abstract}
Cardiovascular disease (CVD) is the leading cause of death worldwide. The effects of testosterone, the primary male sex hormone, on cardiovascular risk have been of special interest due to the increased risk of CVD in men. Although it is well established that testosterone levels decline and cardiovascular mortality increases with age, the association between testosterone and CVD remains unclear. Observational and randomized studies on the effects of endogenous and exogenous testosterone have produced conflicting data, and meta-analyses have been inconclusive, suggesting significant study heterogeneity. Despite a lack of adequately powered randomized controlled trials, large observational studies in the early 2010 s led to advisories on the use of testosterone replacement therapy. Similar advisories have been mandated for certain types of androgen deprivation therapy. Additional research suggests that testosterone shortens the heart-rate -corrected QT interval, improves glycemic control, induces vasodilation, is prothrombotic, and has anti-obesity effects, whereas associations with atherosclerosis and inflammation are less clear. Despite
\end{abstract}

Cardiovascular disease (CVD) is the leading cause of death globally. ${ }^{1}$ Various factors increase the risk of CVD, including diabetes, obesity, hypertension, dyslipidemia, and increasing age. Epidemiologic studies have suggested that men face a higher risk of CVD compared to women, ${ }^{2}$ and evidence supports a role for sex hormones in the modulation of CVD pathogenesis in men and women. Atlhough the protective effect of estrogen on cardiovascular health is well-established, ${ }^{3}$ the effect of testosterone is less clear.

An increased risk of premature cardiovascular events in men initially led to the belief that testosterone had detrimental effects on cardiovascular health. Some large observational and randomized studies have supported this conclusion, whereas

Received for publication April 27, 2021. Accepted May 9, 2021.

Ethics Statement: This research has adhered to all relevant ethical guidelines.

Corresponding author: Dr Geoff H. Werstuck, Thrombosis and Atherosclerosis Research Institute, 237 Barton St East, Hamilton, Ontario L8L 2X2, Canada. Tel.: +1-905 521-2100, ext 40747.

E-mail: geoff.werstuck@taari.ca

See page 1245 for disclosure information.

\section{RÉSUMÉ}

Les maladies cardiovasculaires (MCV) sont la principale cause de décès dans le monde. Les effets de la testostérone, principale hormone sexuelle masculine, sur le risque cardiovasculaire ont suscité un intérêt particulier en raison du risque accru de MCV chez les hommes. S'il est bien établi que le taux de testostérone diminue et que la mortalité cardiovasculaire augmente avec l'âge, l'association entre la testostérone et les MCV demeure obscure. Les études d'observation et à répartition aléatoire sur les effets de la testostérone endogène et exogène ont donné des données contradictoires, et les méta-analyses n'ont pas été concluantes, laissant entrevoir une hétérogénéité importante des études. Malgré un manque d'essais comparatifs à répartition aléatoire, de vastes études d'observation réalisées au début des années 2010 ont conduit à formuler des avis sur l'utilisation du traitement de substitution de la testostérone. Des avis similaires ont été demandés pour certains types de traitements antiandrogéniques. D'après d'autres recherches, la testostérone raccourcirait l'intervalle QT corrigé en fonction de la fréquence cardiaque, améliorerait la maîtrise glycémique,

others have suggested a cardioprotective role for testosterone. Systematic reviews and meta-analyses have generally reported low-quality evidence and hence have been inconclusive. With testosterone therapies being used in the treatment of conditions that affect millions of men worldwide, ${ }^{4}$ the relationship of testosterone to cardiovascular risk and disease must be better understood to inform guidelines for use of these therapies. This review summarizes recent clinical and preclinical studies with the aim to better understand the effect, and possible mechanisms of action, of testosterone on cardiovascular risk. The effect of testosterone on specific cardiovascular risk factors is also assessed.

\section{Molecular Biology of Testosterone}

\section{Biosynthesis and metabolism of testosterone}

Testosterone is the primary sex hormone in men. It is essential for the development of the male reproductive system and secondary sex characteristics. ${ }^{5}$ Following stimulation by the luteinizing hormone (LH), testosterone is synthesized from cholesterol through steroidogenesis. ${ }^{5}$ This synthesis occurs primarily in testicular Leydig cells and, in smaller 
inconclusive evidence on cardiovascular risk and inconsistencies among clinical practice guidelines, millions of men continue to use testosterone replacement and androgen deprivation therapy. In addition to summarizing clinical and preclinical data, this review provides insight on potential mechanisms of action of testosterone on CVD, applications of this knowledge to clinical settings, and avenues for future research. quantities, in the adrenal glands. ${ }^{5}$ The synthesis is regulated by the hypothalamic-pituitary-testicular axis, with increasing testosterone levels activating a negative feedback loop that inhibits the release of gonadotropic releasing hormone $(\mathrm{GnRH})$, follicle-stimulating hormone, and $\mathrm{LH}^{6}$

Secreted testosterone circulates in the blood in its free form or bound to carrier proteins. Sex hormone-binding globulin (SHBG) is the major carrier protein of testosterone, ${ }^{6}$ with approximately $60 \%$ of testosterone bound to SHBG, and an additional $40 \%$ bound to albumin. ${ }^{6}$ Only $1 \%-2 \%$ of testosterone is unbound or free. ${ }^{7}$ Although only free testosterone was historically considered to be biologically available, albumin-bound testosterone is now also accepted as being bioavailable, due to its lower binding affinity.

Bioavailable testosterone can exert its effects directly on androgen receptors (ARs). Alternatively, it may be metabolized to other steroid hormones, such as dihydrotestosterone (DHT) or $17 \beta$-estradiol (E2), or by $5 \alpha$-reductase and aromatase, respectively. ${ }^{5}$ DHT amplifies the effects of testosterone, as it is a highly active metabolite with a greater binding capacity and signalling induction potency. ${ }^{6}$ In men, E2 is produced locally through conversion by aromatase, ${ }^{5}$ an enzyme expressed in multiple tissues, including adipose tissue, bone, and brain.

Testosterone is largely metabolized to androsterone and aetiocholanolone and conjugated with glucuronic or sulphuric acid prior to excretion in the urine. ${ }^{6}$ In those over the age of 60 years, the metabolic clearance rate of testosterone decreases rapidly. ${ }^{8}$ Concurrently, with age, the levels of free and albumin-bound testosterone also decline, whereas SHBG-bound testosterone levels increase. ${ }^{8}$ This decrease results in decreased free testosterone levels and bioavailability. The effect of age on total testosterone concentration is not clear.

\section{Physiological effects of testosterone}

Most physiological effects of testosterone are mediated through its interaction with the AR, a ligand-dependent nuclear receptor. The AR gene spans 8 exons and $90 \mathrm{~kb}$ at locus Xq1112. ' It has 3 major functional domains, each with a unique role in mediating the molecular mechanisms of androgens: N-terminal transcriptional regulatory domain, DNA-binding domain, and C-terminal ligand-binding domain. ${ }^{10}$ Atlhough gene transcription is affected by cell type and age, the AR gene is expressed in most cell types and tissues, with the exception of the spleen. ${ }^{10}$

Androgens have diverse effects on multiple organ systems (Fig. 1). These effects can occur through classical and nonclassical mechanisms. ${ }^{11,12}$ Classical or DNA-binding-dependent signalling involves androgen binding-induced conformational provoquerait une vasodilatation, exercerait un effet prothrombotique et aurait des effets anti-obésité; en revanche, le lien avec l'athérosclérose et l'inflammation est moins claire. Malgré des preuves peu concluantes sur le risque cardiovasculaire et des incohérences quant aux directives de pratique clinique, des millions d'hommes continuent de recourir à des traitements de substitution de la testostérone et antiandrogéniques. En plus de résumer les données cliniques et précliniques, cette analyse donne un aperçu des modes d'action potentiels de la testostérone sur les MCV, des applications de ces connaissances en contexte clinique et des pistes de recherches futures.

changes in the AR, which dissociate from chaperone proteins and expose the AR nuclear location sequence. ${ }^{11}$ The AR/ androgen complex then translocates to the nucleus and forms dimers that bind to specific androgen response promoter elements (AREs) to modulate gene transcription. ${ }^{11}$ Nonclassical or non-DNA binding-dependent signalling occurs within seconds or minutes and does not directly involve transcriptional changes. ${ }^{12}$ Although the specific mechanism is unclear, 2nd messenger pathway activation involving mitogen-activated protein kinase, protein kinase $\mathrm{B}(\mathrm{Akt})$, and extracellular receptor kinase has been implicated, as well as possible indirect gene repression through sequestration of transcription factors (Fig. 2). ${ }^{12}$

\section{Testosterone and Cardiovascular Risk}

\section{Endogenous testosterone levels and cardiovascular risk}

The Massachusetts Male Aging Study established that testosterone levels peak around the age of 30 years, followed by a decline of $1 \%-2 \%$ annually. ${ }^{8}$ This observation led to an interest in exploring the association between low testosterone concentrations and cardiovascular risk. Speculation on the hormone's effects has led to decades of observational studies and reviews.

Many population-based studies have found an inverse correlation between endogenous testosterone levels and all-cause and cardiovascular mortality, especially in older men. A prospective study of elderly men by Laughlin et al. ${ }^{13}$ found that men in the lowest quartile of total testosterone levels had a $40 \%$ increased likelihood of 20-year mortality compared to those with higher levels, which could not be explained by a range of comorbidities and risk factors, including age (hazard ratio $[\mathrm{HR}] 1.40$ [95\% confidence interval $\{\mathrm{CI}\}$ 1.14-1.71]). These results were in accordance with an 8 -year prospective cohort study of male veterans (HR 1.88 [95\% CI 1.342.63]). ${ }^{14}$ Laughlin et al. ${ }^{13}$ also associated lower testosterone levels with increased cardiovascular mortality (HR 1.38 [95\% CI 1.02-1.85]). This finding is consistent with results of the prospective Rotterdam study, which reported an inverse association between testosterone levels in older men and risk and progression of severe aortic atherosclerosis. ${ }^{15}$ The European Prospective Investigation Into Cancer in Norfolk (EPICNorfolk) study, a nested case-control study, similarly reported an inverse relationship between endogenous testosterone concentrations and all-cause mortality and CVD. ${ }^{15}$ 


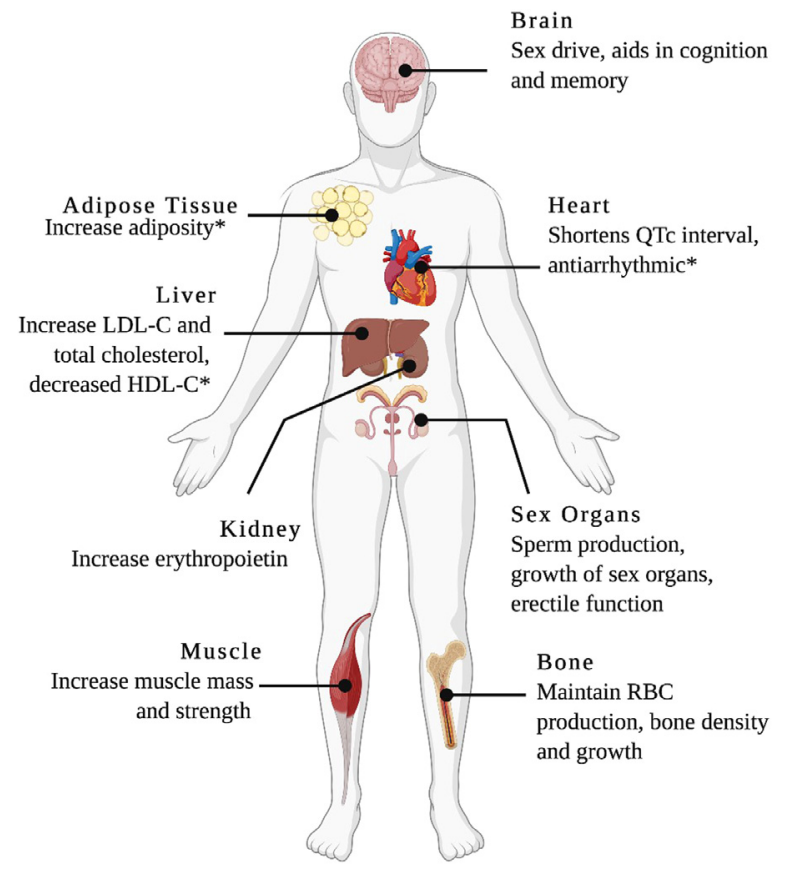

Figure 1. Physiological effects of testosterone: Testosterone has effects on multiple organs, and many of these effects have direct and/or indirect implications for cardiovascular health. HDL-C, highdensity lipoprotein cholesterol; LDL-C, low-density lipoprotein cholesterol; QTc interval, heart-rate-corrected QT interval; RBC, red blood cell. *Inconclusive research on the specific effect. Created with BioRender.com.

In contrast, other studies have found no statistically significant association between testosterone level and cardiovascular mortality. The longitudinal Cardiovascular Health Study failed to find an association between total and free testosterone levels and either incident CVD or mortality in older men. ${ }^{16}$ DHT, however, was associated with these outcomes. ${ }^{16} \mathrm{~A}$ recent prospective study of 552 elderly male subjects found no relationship between endogenous testosterone levels with either risk of coronary artery disease or cerebrovascular or peripheral arterial disease events. ${ }^{17}$ Interestingly, data from the prospective French Three-City (3C) study suggested a "Jshaped" association between serum total testosterone level and risk of ischemic arterial disease in elderly men. ${ }^{18}$ Individuals in the highest and lowest quintiles had an increased risk of ischemic artery disease, as compared to those in the second quintile. ${ }^{18}$ This finding is in direct contrast to findings in previous studies that men with the lowest testosterone levels had the highest cardiovascular risk. ${ }^{13-15}$

Some systematic reviews and meta-analyses have suggested that the conflicting associations, and subsequent lack of firm conclusions, may be due to study heterogeneity and low-quality evidence. ${ }^{19}$ A 2018 meta-analysis of observational studies by Corona et al. ${ }^{19}$ suggested that low baseline endogenous testosterone levels predicted overall and cardiovascular mortality. However, the authors indicated that the data may have been influenced by publication bias. ${ }^{19}$ A meta-analysis by Araujo et $\mathrm{al}^{20}$ also found an association between testosterone and overall mortality; however, significant heterogeneity between studies suggested that the effects may have been driven by cohort differences. Ruige et al. ${ }^{21}$ reported a weak pooled protective effect of total testosterone on CVD in healthy men. Similar to Araujo et al., ${ }^{20}$ the authors found significant heterogeneity $(P<0.0001)$, with population age and publication year identified as sources. ${ }^{21}$ Following stratification by age, an inverse association was found between total testosterone and CVD in men above the age of 70 years, whereas no association was found in younger men. ${ }^{21}$ This difference indicates that the contradicting results of observational studies may be due to varying baseline population characteristics. However, it is important to note the limitations associated with observational studies, including increased susceptibility to bias and confounding. Further, many studies conducted only a single testosterone measurement, which may have been impacted by significant diurnal variation. ${ }^{22}$ Most studies also did not consider the clinical presentation of testosterone deficiency.

Thus, although many studies have found inverse associations between endogenous testosterone levels and cardiovascular risk and mortality, conflicting results and heterogeneous study populations have prevented firm conclusions from being drawn.

\section{Testosterone replacement therapy}

Despite a lack of clarity on the relationship between endogenous testosterone and cardiovascular risk, testosterone replacement therapy (TRT) is widely used, especially in older men with low serum testosterone levels. TRT does have benefits, such as improved sexual function, increased skeletal muscle mass, and increased bone mineral density. ${ }^{23}$ The Copenhagen Study Group conducted one of the first randomized controlled trials (RCTs) reporting an increased mortality level in men treated with testosterone, although the effect was not statistically significant (risk ratio [RR] 1.17 [95\% CI $0.65-2.15]) .{ }^{24}$ The infeasibility "to demonstrate-in the foreseeable future- a beneficial effect of testosterone by continuing the study" led to the premature end of the trial. ${ }^{24}$ Despite this finding, testosterone sales increased 100 -fold from the 1980 s to the 2010s, with a 40 -fold increase in Canada from 2000 to 2011 . $^{25}$

In the early 2010 s, certain large observational and randomized studies found an increased cardiovascular risk to be associated with testosterone therapy. ${ }^{26}$ In 2010 , the Testosterone in Older Men (TOM) trial had to be stopped prematurely due to the increased incidence of cardiovascular events in the intervention group. ${ }^{26}$ The trial involved 209 elderly community-dwelling men with limited mobility, randomized to receive placebo or testosterone. ${ }^{26}$ Men in the highest quartile of testosterone levels were at elevated risk for cardiovascular events (HR 2.4; $P=0.05$ ) compared to other subjects. ${ }^{26}$ Vigen et al. ${ }^{27}$ later conducted a retrospective cohort study to determine the effects of testosterone therapy in veterans undergoing coronary angiography with preexisting low testosterone levels. Cox proportional hazard models indicated an increased risk of adverse cardiovascular outcomes in men receiving testosterone therapy (HR 1.29 [95\% CI 1.04$1.58]) .{ }^{29}$ In accordance with these results, a retrospective cohort study by Finkle et al..$^{28}$ reported a statistically significant elevation of myocardial infarction rates post-prescription of testosterone, compared to pre-prescription, with an 


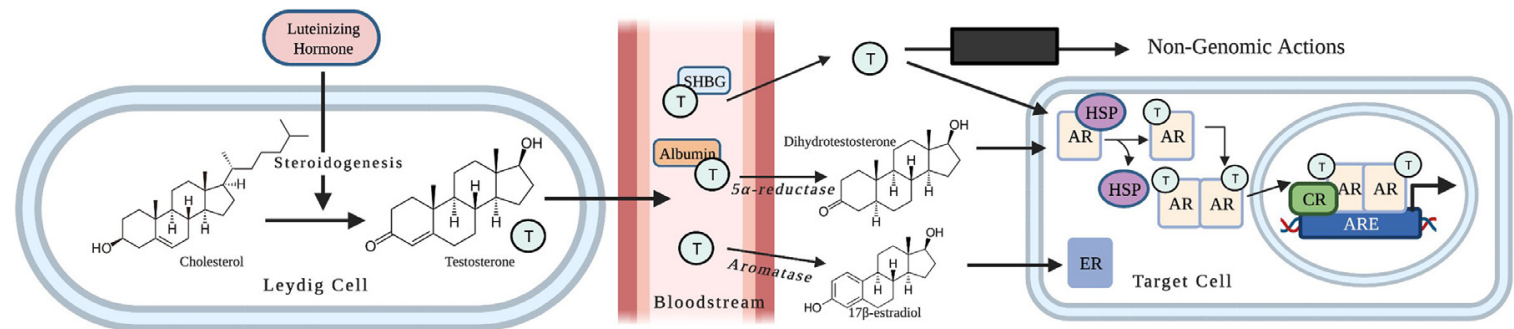

Figure 2. Biochemical pathway of testosterone: Testosterone, synthesized from cholesterol following luteinizing hormone (LH) stimulation, travels through the bloodstream from Leydig cells to target cells. Testosterone can be converted to dihydrotestosterone (DHT) or 17 $\beta$-estradiol (E2). Testosterone and DHT bind to the androgen receptor (AR) to regulate androgen-responsive genes. Testosterone can also act via non-genomic pathways. ARE, androgen response element; $\mathrm{CR}$, coregulator; ER, estrogen receptor; $\mathrm{H}$, hydrogen; $\mathrm{HSP}$, heat shock protein; $\mathrm{O}$, oxygen; OH, hydroxide; SHBG, sex-hormone binding globulin; T, testosterone. Created with BioRender.com.

especially pronounced effect in men over the age of 75 years (RR 3.43 [95\% CI 1.54-7.66]). In men aged <65 years, the excess risk was limited to those with a history of heart disease (RR 2.90 [95\% CI 1.49-5.62]). ${ }^{28}$ Further supporting these results, the Testosterone Trials (TTrials) found a statistically significant 1-year increase in noncalcified plaque volume (estimated difference $41 \mathrm{~mm}^{3}$ [95\% CI 14 to $67 \mathrm{~mm}^{3}$ ]) in hypogonadal elderly men receiving testosterone therapy, compared to the placebo group. ${ }^{29}$ No statistically significant difference was found between the intervention and control groups in the number of cardiovascular events or the calcified plaque progression. $^{29}$

The indication of an association between testosterone therapy and risk for adverse cardiovascular events prompted the US Food and Drug Administration (FDA) to issue a safety warning on testosterone therapy for older men, which was

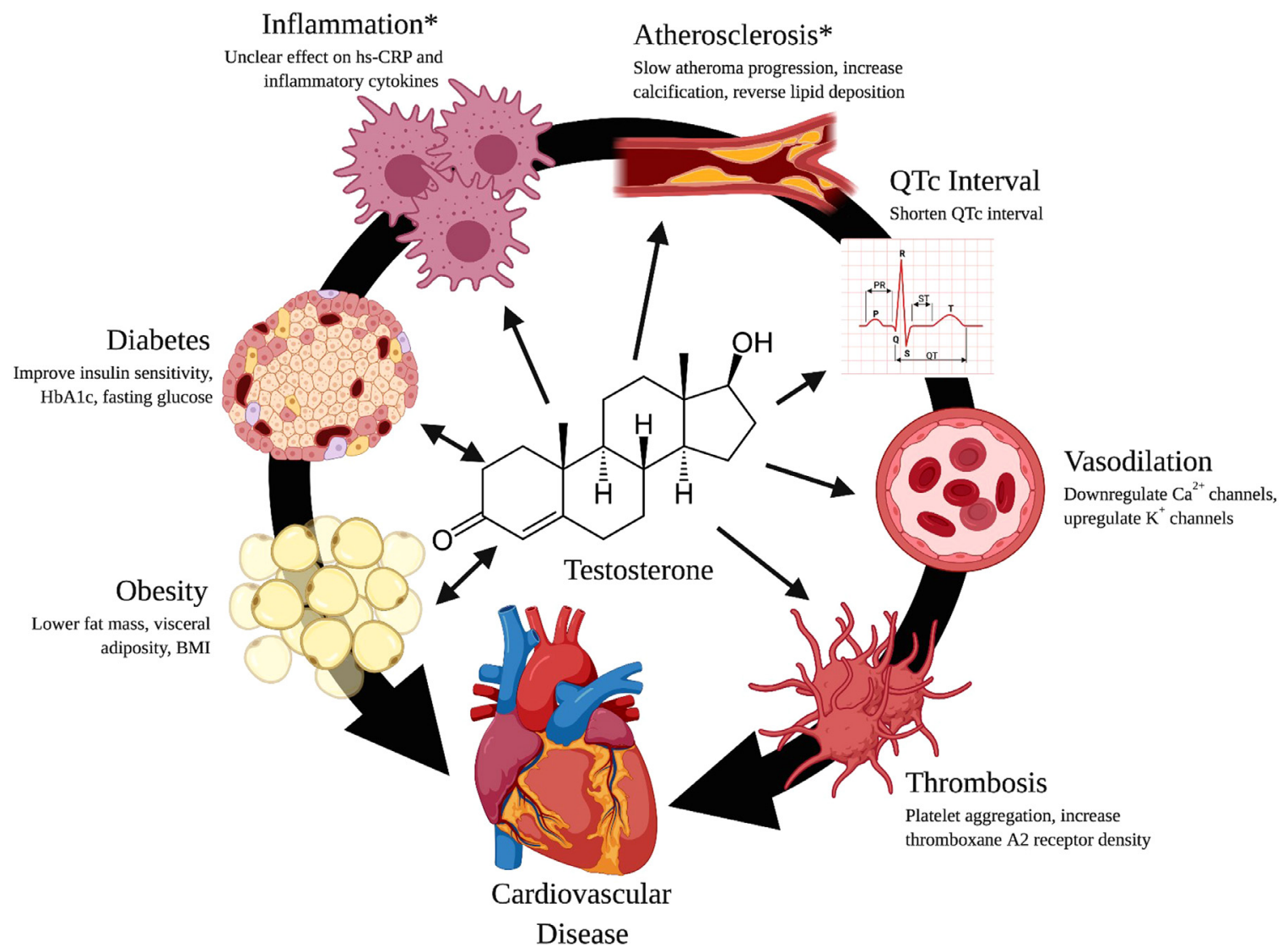

Figure 3. Effects of testosterone on cardiovascular risk: graphical depiction of the hypothesized mechanisms of action of testosterone on various cardiovascular risk factors. BMI, body mass index; Ca, calcium; $\mathrm{H}$, hydrogen; HbA1c, hemoglobin A1c; hs-CRP, high-sensitivity C-reactive protein; $\mathrm{K}$, potassium; O, oxygen; $\mathrm{OH}$, hydroxide; QTc interval, heart-rate-corrected QT interval. *Research in the area is inconclusive. $\Leftrightarrow$ Likely a bidirectional relationship. Created with BioRender.com. 
followed by a reduction in testosterone prescriptions. ${ }^{30}$ The safety warning cautioned against the use of testosterone therapy for aging-related decline and reinforced the current approval of testosterone products for hypogonadal men only. ${ }^{30}$ However, it is important to note that the methodology and reliability of the aforementioned studies have since been questioned. The TOM trials lacked predetermined cardiovascular endpoints, as the trial was not designed to investigate cardiovascular health. ${ }^{26}$ Further, despite a sample with a high prevalence of comorbidities, including hypertension, obesity, diabetes mellitus, and preexisting CVD, only 4 major adverse cardiovascular events occurred, although all were in the testosterone group. ${ }^{26}$ These results were not replicated in a later trial with a similar population and testosterone-administration technique. ${ }^{31}$ Both the Vigen et al. ${ }^{27}$ and Finkle et al. ${ }^{28}$ studies were retrospective in nature, which poses inherent design limitations that make it difficult to draw definitive conclusions from the data. Questions also have been raised regarding the methodological validity and statistical analysis techniques in the study by Vigen et al. ${ }^{27}$

In contrast to these studies, others have reported a protective effect of testosterone therapy on cardiovascular health. Cheetham et al. ${ }^{32}$ found a lower risk of cardiovascular outcomes in androgen-deficient men who had received TRT (HR 0.67 [95\% CI 0.62-0.73]), analyzed retrospectively for a median of 3.4 years. In a recent matched cohort study, shortterm testosterone therapy increased the risk of mortality and cardiovascular events in men over the age of 65 years, whereas longer-term therapy was associated with reduced risk of mortality, adverse cardiovascular events, and prostate cancer. ${ }^{33}$

As a result of these conflicting results, a recent meta-analysis found no significant association between testosterone therapy and cardiovascular events and mortality, and it reported low-quality evidence due to bias, inconsistencies, and imprecision. ${ }^{34}$ This disparity in results has led to inconsistencies among clinical practice guidelines. Although all acknowledge the possible cardiovascular risks of testosterone therapy, there is disagreement on the minimum amount of time following a major cardiovascular event that an individual should receive testosterone therapy. ${ }^{35}$

Adequately powered randomized clinical trials designed to assess cardiovascular events are required to definitively determine the effect of testosterone therapy on cardiovascular risk. The Testosterone Replacement Therapy for Assessment of Long-term Vascular Events and Efficacy ResponSE in Hypogonadal Men (TRAVERSE) study is an ongoing clinical trial designed to measure the time to major adverse cardiovascular events in hypogonadal men, aged 45 to 80 years, with increased risk or evidence of CVD. ${ }^{36}$ The study commenced in May 2018 and is expected to be completed in June 2022, with 6000 planned participants randomized to receive topical testosterone or placebo. ${ }^{36}$ This clinical trial will play an important role in determining the safety of TRT in hypogonadal men.

\section{Androgen deprivation therapy}

In contrast to the use of TRT in hypogonadal men, androgen deprivation therapy (ADT) is commonly used in the treatment of advanced prostate cancer. Prostate cancer is the second most frequent malignancy in men worldwide. ${ }^{4}$ In
1941, Huggins and Hodges ${ }^{37}$ were the first to demonstrate the beneficial effects of castration and estrogen injections in men with metastatic prostate cancer. Since then, the introduction of chemical castration and hormonal therapy has resulted in a decline in use of physical castration. GnRH agonists downregulate the $\mathrm{GnRH}$ receptors, thus decreasing the release of $\mathrm{LH}$ and blocking stimulation of testosterone secretion. ${ }^{38}$ They lead to castration levels of testosterone after a couple of weeks, but the GnRH agonist-induced stimulation of LH causes an initial increase in testosterone level. ${ }^{38} \mathrm{GnRH}$ antagonists may be used in those for whom GnRH agonist therapy is not appropriate, although certain $\mathrm{GnRH}$ antagonists have been associated with incident anaphylaxis. ${ }^{39}$ Other drug classes are also used, including antiandrogens, $5 \alpha$-reductase inhibitors, and adrenal ablating drugs. ${ }^{40}$

Valid concerns remain regarding the possibility of testosterone therapy increasing the risk of prostate cancer. Although the relationship between testosterone therapy and the incidence of prostate cancer is still debated, the Endocrine Society recommends against testosterone therapy in men with an increased risk of prostate cancer. ${ }^{41}$ In contrast, the American Urological Association advises clinicians to "inform patients of the absence of evidence linking testosterone therapy to the development of prostate cancer," citing RCTs that have found no significant difference in prostate cancer diagnosis in testosterone-deficient men treated with testosterone, as compared to placebo. ${ }^{42}$ Observational studies, including the one by Ory et al., ${ }^{43}$ reported similar conclusions.

The effects of the artificial lowering of testosterone levels by ADT on an individual's overall health has also been studied extensively. Using Surveillance, Epidemiology and End Results (SEER) Medicare data, Keating et al. ${ }^{44}$ found that prostate cancer patients aged 66 years or older receiving $\mathrm{GnRH}$ agonists had an elevated risk of diabetes (HR 1.44 [95\% CI 1.34-1.55]), coronary artery disease (HR 1.16 [95\% CI 1.10-1.21]), myocardial infarction (HR 1.11 [95\% CI 1.01-1.21]), and sudden cardiac death (HR 1.16 [95\% CI 1.05-1.27]). Interestingly, these same effects were not noticed in the orchiectomy group, although that group was underpowered. ${ }^{44}$ A similar retrospective study using SEER-Medicare data reported a $20 \%$ increased risk of serious cardiovascular morbidity in newly diagnosed prostate cancer patients who received ADT for at least 1 year, as compared to patients who did not receive ADT. ${ }^{45}$ Another study, based on data from the Cancer of Prostate Strategic Urologic Research Endeavor (CaPSURE) database, associated ADT with significantly increased risk of cardiovascular mortality in patients also receiving radial proctectomy (HR 2.6 [95\% CI 1.44.7]). ${ }^{46}$ The retrospective nature of these studies is inherently prone to increased bias, preventing definitive conclusions from being drawn. In the same year, however, D'Amico et al. ${ }^{47}$ pooled data from 3 RCTs examining short-term androgen suppression therapy and found that older men who received androgen suppression therapy had shorter times to fatal myocardial infarctions than those who did not receive therapy. Cumulative incidence did not differ between the 2 groups. ${ }^{47}$ These studies led the American Health Association, the American Cancer Society, and the American Urological Association ${ }^{48}$ to issue a joint statement in 2010, declaring it to be "appropriate to state that there may be a relation between ADT and cardiovascular risk." Soon after, the FDA 
also mandated the addition of warnings of increased risk of diabetes and CVD as a result of GnRH agonist use in men with prostate cancer. ${ }^{49}$

Since these advisories were issued, additional observational studies have been conducted to assess the impact of ADT on cardiovascular outcomes. The results have been mixed. A retrospective matched cohort of nearly 40,000 older men with prostate cancer found no association of ADT with acute myocardial infarction (HR 0.91 [95\% CI 0.84-1.00]) or sudden cardiac death (HR 0.96 [95\% CI 0.83-1.10]). ${ }^{50}$ However, a prospective study did find an increased risk of heart failure in men with localized prostate cancer and without preexisting CVD (adjusted HR 1.81 [95\% CI 1.40-2.32]). ${ }^{51}$ This association was not replicated in men with preexisting $\mathrm{CVD}^{51}$ and is in contrast to previous studies that have found an association only in patients with comorbidities, ${ }^{52}$ and nonsignificant associations of risk factors with incident myocardial infarction during ADT. ${ }^{53}$

Meta-analyses on the topic have also been mixed, with significant differences between the findings of RCTs and observational studies. Carneiro et al. ${ }^{54}$ found a significant association between ADT and myocardial infarction in observational studies (odds ratio 2.01 [95\% CI 1.90-2.13]), but only an association with nonfatal cardiovascular events for RCTs (odds ratio 1.55 [95\% CI 1.09-2.20]). Similarly, metaanalysis of RCTs did not find an association of ADT with cardiovascular mortality. ${ }^{55}$ It should be noted, however, that the cardiovascular effects associated with ADT differ based on the type of therapy. Much of the research has been with $\mathrm{GnRH}$ agonists, which have been associated with increased cardiovascular risk. ${ }^{56}$ This increased risk may be due to the stimulation of T-cell proliferation and subsequent differentiation into the proinflammatory phenotype, or initial increase of folliclestimulating hormone, a hormone that has been associated with fat accumulation and acceleration of lipogenesis and lipid droplet formation. ${ }^{57}$ The PRONOUNCE trial (A Trial Comparing Cardiovascular Safety of Degarelix Versus Leuprolide in Patients With Advanced Prostate Cancer and Cardiovascular Disease) examining the cardiovascular safety of $\mathrm{GnRH}$ agonist compared to GnRH antagonists, is currently underway.

\section{Molecular Mechanisms of the Action of Testosterone on Cardiovascular Risk Factors}

\section{The effect of testosterone on cardiovascular physiology}

Testosterone has a variety of effects on cardiovascular physiology, which may impact the hormone's effect on CVD (Fig. 3). Clinical data strongly suggest that low testosterone levels are associated with longer heart-rate-corrected QT intervals and that TRT results in interval shortening. ${ }^{59}$ Prolonged heart-rate-corrected QT intervals can result in an increased ventricular arrhythmia incidence and subsequent sudden cardiac death. ${ }^{60}$

The majority of preclinical studies have found testosterone to have vasodilatory effects. It is believed that this process involves the downregulation of L-type voltage-gated calcium channels $^{61}$ and upregulation of calcium-activated potassium channels. ${ }^{62}$ The immediacy of the vasodilation has raised questions as to whether the underlying mechanism involves non- genomic actions of testosterone. Further, testosterone has been shown to increase cardiac contractility ${ }^{61}$ and cardiomyocyte relaxation speed. ${ }^{63}$ It is not clear whether these vascular effects are dependent on the endothelium and/or AR. It is important to note that these findings oppose those of other studies reporting that testosterone intensifies vasocontraction. ${ }^{64}$

\section{The association of testosterone with atherosclerosis and thrombosis}

Nettleship et al. ${ }^{65}$ found that testosterone slows atheroma development and reverses lipid deposition in the artery wall. Although the effect of E2 on atheroma progression is debated, a possible mechanism includes estradiol-dependant suppression of tumour necrosis factor $-\alpha$ induced vascular cell adhesion protein 1 (VCAM-1) expression. ${ }^{66}$

Some observational studies, including one by Mäkinen et al., ${ }^{67}$ have reported inverse correlations between testosterone and intima-media thickness, a surrogate marker for atherosclerosis. However, due to the nature of the studies, reverse causality cannot be ruled out. Although there is a lack of RCTs reporting directly on atherosclerosis, some have reported on carotid intima-media thickness and plaque calcification. A small RCT found significant beneficial effects of testosterone on carotid intima-media thickness, ${ }^{68}$ whereas larger trials, such as the TTrials, have failed to support this conclusion. ${ }^{29}$ Testosterone may also impact plaque stability through effects on endothelial progenitor cells, which are related to vessel integrity maintenance and are inversely associated with carotid intima-media thickness. Not only do hypogonadal men exhibit lower levels of endothelial progenitor cells, but these cells appear to increase in proliferation and migration in an AR-dependent manner. ${ }^{69}$

Dyslipidemia, including elevated low-density lipoprotein and total cholesterol levels, is a major risk factor for atherosclerosis progression. Many trials, including the $\mathrm{TOM}^{26}$ and TTrials, ${ }^{29}$ have indicated that TRT results in lower total and low-density lipoprotein cholesterol levels. Although the effect on high-density lipoprotein is unclear, it is hypothesized that prolonged testosterone administration may restabilize levels following cholesterol transport normalization. ${ }^{70}$ Because of the varying effects on lipoproteins, the overall effect of testosterone on lipid profile and cardiovascular risk is unknown. The effect of testosterone on these parameters in various populations has been the subject of debate in many meta-analyses. ${ }^{7}$

Testosterone has been found to have prothrombotic effects, increasing the risk of myocardial infarction and stroke following atherosclerotic plaque rupture. Proposed mechanisms include hematocrit stimulation-induced platelet aggregation and increased thromboxane A2 receptor density on platelets. ${ }^{72}$ However, clinical trials have not found corresponding effects on coagulation. ${ }^{73}$

\section{The association of testosterone with diabetes}

In 1978, Shahwan et al. ${ }^{74}$ established that male diabetics have lower levels of endogenous testosterone, compared to nondiabetic men. Atlhough most clinical data have since supported this conclusion, even after controlling for obesity, the direction of the relationship is less clear. ${ }^{75}$ Some studies have found a beneficial effect of testosterone administration on 
glycemic control, including improved insulin sensitivity, HbAlc level, and fasting blood glucose level. ${ }^{76}$ Further, research on prostate cancer patients found that ADT is associated with hyperglycemia and impaired $\beta$-cell function. ${ }^{77}$

Possible mechanisms include non-genomic activation of insulin receptor signalling factors, including Akt, Erk, and $\mathrm{mTOR}$, increased expression of insulin-receptor- $\beta$, insulin receptor substrate-1, Akt-2, and GLUT4 transporter, and increased expression of glycolysis enzymes. ${ }^{70}$ Knockout models have indicated that deficiencies in $5 \alpha$-reductase and/or the AR may result in hepatic steatosis and insulin resistance. ${ }^{78}$ The effect of testosterone on pancreatic $\beta$-cells is less clear; some studies have reported increased AR-dependant hyperglycemic decomposition, ${ }^{79}$ whereas others have found a protective effect. ${ }^{80}$ Despite these studies, the Endocrine Society has maintained that testosterone therapy is not recommended for improving glycemic control in men with type 2 diabetes. ${ }^{41}$

Ballester et al. ${ }^{81}$ found that the administration of insulin restores testosterone, $\mathrm{LH}$, and follicle-stimulating hormone levels, indicating that diabetes may cause low testosterone levels. Clinical data have also indicated that Leydig cell response and $\mathrm{LH}$ production are lower in men with insulin resistance. ${ }^{82}$ These studies indicate that a more complex bidirectional relationship between diabetes and testosterone is perhaps more likely.

\section{The association of testosterone with obesity}

Unlike the relationship of other cardiovascular risk factors to testosterone levels, the inverse association of testosterone with obesity is well established. Various mechanisms have been proposed to underlie this relationship. Preclinical studies suggest that testosterone promotes the differentiation of pluripotent stem cells to the myogenic lineage and inhibits their commitment to the adipogenic lineage. ${ }^{83}$ At a later stage, testosterone may affect the Wnt-signalling pathway and $\beta$-catenin, inhibiting further differentiation of certain preadipocytes. ${ }^{84}$ Testosterone may also decrease abdominal fat through the stimulation of lipolysis and inhibition of adipogenesis. ${ }^{85}$

The opposite directional relationship has also been suggested, such that adiposity may decrease testosterone production. Increased stimulation of leptin receptors on Leydig cells can attenuate LH stimulation and thus lower testosterone production. ${ }^{86}$ The use of aromatase inhibitors or DHT has resulted in the attenuation of the hormone's beneficial effects, indicating an important role of E2. As aromatase is primarily located in adipose tissue, excess adiposity can lead to increased conversion of testosterone into E2 and lowered serum testosterone levels. ${ }^{71}$ However, it is important to note that the lower testosterone levels eventually lead to lower E2 levels, resulting in increased visceral fat and insulin resistance; this is known as the hypogonadism-obesity cycle. ${ }^{87}$

Adiponectin is an adipocytokine of which the levels are inversely related to cardiovascular risk. Adiponectin levels are also inversely associated with testosterone level, although it is unclear if this is a direct effect or indirectly mediated through reduced adipocyte count. ${ }^{88}$ All in all, these studies indicate a complex, likely bidirectional association between obesity and testosterone level, regulated by androgen and estrogen receptors.

\section{The association of testosterone with inflammation}

As inflammation is a known risk factor for atherosclerosis and CVD, there has been interest in exploring the effects of testosterone on inflammation. Results of studies comparing the levels of high sensitivity C-reactive protein and inflammatory cytokines have been largely conflicting. ${ }^{71}$ Whether any observed effects are directly or indirectly due to age or obesity is unknown. ${ }^{71}$ Although Crisostomo et al.$^{89}$ indicated that signalling proteins $\mathrm{p} 38$ and SPAK/JNK, associated with myocardial inflammation, are involved in testosterone-induced exacerbation of inflammation, Rettew et al..$^{0}$ found toll-like receptor-4 to be related to protective effects of testosterone. Some studies have reported anti-inflammatory effects through the suppression of proinflammatory cytokines and enhancement of anti-inflammatory cytokines. ${ }^{91}$ Others, however, have found an increase or no significant changes in high sensitivity C-reactive protein, interleukin (IL)-6, and IL$\beta$ levels. ${ }^{70}$ Preclinical studies have also indicated that IL- 6 and tumour necrosis factor $-\alpha$ are capable of reducing testosterone levels. ${ }^{92}$ Thus, it is important to note that if an association does exist, it may be bidirectional.

\section{The interplay between testosterone and physical activity}

Extensive data have shown an association between low physical activity levels and cardiovascular risk factors, including metabolic syndrome, ${ }^{93}$ type 2 diabetes, ${ }^{94}$ obesity, ${ }^{95}$ and hypertension. ${ }^{96}$ The American Heart Association has declared sedentary behaviour to be a modifiable risk factor for CVD and diabetes mellitus, ${ }^{97}$ and many other organizations recommend physical activity to increase cardiorespiratory fitness. ${ }^{98}$ Interestingly, in multiple RCTs, this effect of exercise on improved metabolic profile, including fat-free muscle mass and glycemic control, was enhanced by testosterone administration in hypogonadal men. ${ }^{76,99}$

The relationship between physical activity and testosterone levels is still unclear. Although some observational studies have found a positive association between testosterone levels and physical activity in younger and older men, ${ }^{100,101}$ others have failed to find an association. ${ }^{102}$ Many intervention studies specifically designed to assess the effect of physical activity have found increases in testosterone levels following a physical activity intervention. ${ }^{103,104}$ Age further affects this relationship, as the increase in free testosterone following resistance exercise is significantly diminished in older and middle-aged men, compared to that in younger age groups. ${ }^{105}$

Given the correlation of physical activity with various cardiovascular risk factors, it is unclear whether any observed associations with testosterone level are directly or indirectly mediated by one or more of the risk factors. However, it is important to further understand the interplay between the 2 variables in mediating risk and affecting the success of targeted interventions in men involving testosterone therapies and/or physical activity.

\section{Conclusion and Future Directions}

Given the prevalence and morbidity of CVD, it is important to clarify potential risk factors, especially in men, as they face higher cardiovascular risk than women. Testosterone, the major sex hormone in men, has been a primary candidate in 
studies of cardiovascular risk. Despite decades of research on the topic, clinical and preclinical data on the effects of exogenous and endogenous testosterone have produced contradictory and/or inconclusive results. In spite of this lack of clarity, many men are currently undergoing TRT or ADT.

It is thus imperative to conduct adequately powered RCTs, such as the TRAVERSE ${ }^{36}$ and PRONOUNCE ${ }^{58}$ trials, designed to study the effect of testosterone on cardiometabolic health, to conclusively determine the cardiovascular effects and safety of associated therapies. Although these trials are assessing outcomes in men with hypogonadism and prostate cancer, it is also important to study effects in older men who do not have these conditions, as they have an increased likelihood of using testosterone therapies. Although this review is focused primarily on the role of testosterone in men, possible differential effects of the hormone in women must be considered in future studies. Moreover, there must be further investigation into mechanisms of action of testosterone. In the meantime, however, it is important for patients to be advised of the possible cardiovascular risk associated with testosterone therapies and encouraged to make informed decisions while being mindful of study limitations.

\section{Funding Sources}

This work was supported by an operational grant from the Canadian Institutes for Health Research (PJT-166092). GHW holds the International Society on Thrombosis and Haemostasis (ISTH)-McMaster Chair in Thrombosis and Haemostasis Research and is supported by an Heart and Stroke Foundation of Canada (HSFC) Ontario Mid-Career Investigator Award.

\section{Disclosures}

The authors have no conflicts of interest to disclose.

\section{References}

1. World Health Organization. Cardiovascular diseases (CVDs). Available at: https://www.who.int/en/news-room/fact-sheets/detail/cardiovascular-diseases-(cvds). Accessed February 10, 2021.

2. Kappert K, Böhm M, Schmieder R, et al. Impact of sex on cardiovascular outcome in patients at high cardiovascular risk: analysis of the telmisartan randomized assessment study in ACE-intolerant subjects with cardiovascular disease (TRANSCEND) and the ongoing telmisartan alone and in combination with ramipril global end point trial (ONTARGET). Circulation 2012;126:934-41.

3. Zhao D, Guallar E, Ouyang P, et al. Endogenous sex hormones and incident cardiovascular disease in post-menopausal women. J Am Coll Cardiol 2018;71:2555-66.

4. Rawla P. Epidemiology of prostate cancer. World J Oncol 2019;10:63-89.

5. Li L, Zirkin BR, Papadopoulos V. Leydig cell androgen synthesis. Encyclopedia of Reproduction. Baltimore: Elsevier; 2018. p. 215-21.

6. Brooks RV. Androgens. Clin Endocrinol Metab 1975;4:503-20.

7. Mayo Clinic Laboratories. Testosterone, total, bioavailable, and free, serum. Available at: https://www.mayocliniclabs.com/test-catalog/Clinical+and+Interpretive/83686. Accessed February 10, 2021.
8. Gray A, Feldman HA, Mckinlay JB, Longcope C. Age, disease, and changing sex hormone levels in middle-aged men: results of the Massachusetts Male Aging Study. J Clin Endocrinol Metab $1991 ; 73: 1016-25$

9. Brown CJ, Goss SJ, Lubahn DB, et al. Androgen receptor locus on the human X chromosome: regional localization to Xq11-12 and description of a DNA polymorphism. Am J Hum Genet 1989;44:264-9.

10. Lindzey J, Kumar MV, Grossman M, Young C, Tindall DJ. Molecular mechanisms of androgen action. Vitam Horm 1994: 383-432.

11. Eder IE, Culig Z, Putz T, et al. Molecular biology of the androgen receptor: from molecular understanding to the clinic. Eur Uro 2001;40:241-51.

12. Kallio PJ, Poukka H, Moilanen A, Jänne OA, Palvimo JJ. Androgen receptor-mediated transcriptional regulation in the absence of direct interaction with a specific DNA element. Molec Endocrinol 1995;9:1017-28.

13. Laughlin GA, Barrett-Connor E, Bergstrom J. Low serum testosterone and mortality in older men. J Clin Endocrinol Metab 2008;93:68-75.

14. Shores MM, Matsumoto AM, Sloan KL. Kivlahan DR Low serum testosterone and mortality in male veterans. Arch Intern Med 2006;166:1660-5.

15. Khaw KT, Dowsett M, Folkerd E, et al. Endogenous testosterone and mortality due to all causes, cardiovascular disease, and cancer in men: European prospective investigation into cancer in Norfolk (EPIC-Norfolk) prospective population study. Circulation 2007;116:2694-701.

16. Shores MM, Biggs ML, Arnold AM, et al. Testosterone, dihydrotestosterone, and incident cardiovascular disease and mortality in the cardiovascular health study. J Clin Endocrinol Metab 2014;99:2061-8.

17. Collet T-H, Ewing SK, Ensrud KE, et al. Endogenous testosterone levels and the risk of incident cardiovascular events in elderly men: the MrOS Prospective Study. J Endocr Soc 2020;4:1-15.

18. Soisson V, Brailly-Tabard S, Helmer C, et al. A J-shaped association between plasma testosterone and risk of ischemic arterial event in elderly men: the French 3C Cohort Study. Maturitas 2013;75:282-8.

19. Corona G, Rastrelli G, di Pasquale G, et al. Endogenous testosterone levels and cardiovascular risk: meta-analysis of observational studies. J Sex Med 2018;15:1260-71.

20. Araujo AB, Dixon JM, Suarez EA, et al. Endogenous testosterone and mortality in men: a systematic review and meta-analysis. J Clin Endocrinol Metab 2011;96:3007-19.

21. Ruige JB, Mahmoud AM, de Bacquer D, Kaufman JM. Endogenous testosterone and cardiovascular disease in healthy men: a meta-analysis. Heart 2011;97:870-5.

22. Brambilla DJ, Matsumoto AM, Araujo AB, McKinlay JB. The effect of diurnal variation on clinical measurement of serum testosterone and other sex hormone levels in men. J Clin Endocrinol Metab 2009;94:907-13.

23. Spitzer M, Huang G, Basaria S, Travison TG, Bhasin S. Risks and benefits of testosterone therapy in older men. Nature Rev Endocrinol 2013;9:414-24

24. Gluud C. Testosterone treatment of men with alcoholic cirrhosis: a double-blind study. Hepatology 1986;6:807-13.

25. Handelsman DJ. Global trends in testosterone prescribing, 2000-2011: expanding the spectrum of prescription drug misuse. Med J Aust 2013;199:548-51. 
26. Basaria S, Coviello AD, Travison TG, et al. Adverse events associated with testosterone administration. N Engl J Med 2010;363:109-22.

27. Vigen R, O’Donnell CI, Barón AE, et al. Association of testosterone therapy with mortality, myocardial infarction, and stroke in men with low testosterone levels. JAMA 2013;310:1829-36.

28. Finkle WD, Greenland S, Ridgeway GK, et al. Increased risk of nonfatal myocardial infarction following testosterone therapy prescription in men. PLoS ONE 2014;9:e85805.

29. Budoff MJ, Ellenberg SS, Lewis CE, et al. Testosterone treatment and coronary artery plaque volume in older men with low testosterone. JAMA 2017;317:708-16.

30. US Food and Drug Administration. FDA Drug Safety Communication: FDA cautions about using testosterone products for low testosterone due to aging; requires labeling change to inform of possible increased risk of heart attack and stroke with use. Available at: https:// www.fda.gov/drugs/drug-safety-and-availability/fda-drug-safety-communication-fda-cautions-about-using-testosterone-products-low-testosterone-due. Accessed February 10, 2021.

31. O'Connell MDL, Roberts SA, Srinivas-Shankar U, et al. Do the effects of testosterone on muscle strength, physical function, body composition, and quality of life persist six months after treatment in intermediate-frail and frail elderly men? J Clin Endocrinol Metab 2011;96:454-8.

32. Cheetham TC, An JJ, Jacobsen SJ, et al. Association of testosterone replacement with cardiovascular outcomes among men with androgen deficiency. JAMA Intern Med 2017;177:491-9.

33. Wallis CJD, Lo K, Lee Y, et al. Survival and cardiovascular events in men treated with testosterone replacement therapy: an intention-to-treat observational cohort study. Lancet Diab Endocrinol 2016;4:498-506.

34. Alexander GC, Iyer G, Lucas E, Lin D, Singh S. Cardiovascular risks of exogenous testosterone use among men: a systematic review and metaanalysis. Am J Med 2017;130:293-305.

35. Pelzman DL, Hwang K. Testosterone therapy: Where do the latest guidelines agree and differ? Curr Opin Endocrinol Diabetes Obes 2020;27:397-403.

36. National Institutes of Health. A study to evaluate the effect of testosterone replacement therapy (TRT) on the incidence of major adverse cardiovascular events (MACE) and efficacy measures in hypogonadal men. Available at: https://www.clinicaltrials.gov/ct2/show/NCT03518034. Accessed February 10, 2021.

37. Huggins C, Hodges CV. Studies on prostatic cancer. I. The effect of castration, of estrogen and of androgen injection on serum phosphatases in metastatic carcinoma of the prostate. CA Cancer J Clin 1972;22:232-40.

38. Tolis G, Ackman D, Stellos A, et al. Tumor growth inhibition in patients with prostatic carcinoma treated with luteinizing hormonereleasing hormone agonists. Proc Natl Acad Sci U S A 1982;79:165862.

39. Koechling W, Hjortkjaer R, Tankó LB. Degarelix, a novel GnRH antagonist, causes minimal histamine release compared with cetrorelix, abarelix and ganirelix in an ex vivo model of human skin samples. Brit J Clin Pharmacol 2010;70:580-7.

40. Sharifi N, Gulley JL, Dahut WL. Androgen deprivation therapy for prostate cancer. JAMA 2005;294:238-44.

41. Bhasin S, Brito JP, Cunningham GR, et al. Testosterone therapy in men with hypogonadism: an Endocrine Society clinical practice guideline. J Clin Endocrinol Metab 2018;103:1715-44.
42. Mulhall JP, Trost LW, Brannigan RE, et al. Evaluation and management of testosterone deficiency: AUA guideline. J Urol 2018;200:423-32.

43. Ory J, Flannigan R, Lundeen C, et al. Testosterone therapy in patients with treated and untreated prostate cancer: impact on oncologic outcomes. J Urol 2016;196:1082-9.

44. Keating NL, O'Malley AJ, Smith MR. Diabetes and cardiovascular disease during androgen deprivation therapy for prostate cancer. J Clin Oncol 2006;24:4448-56.

45. Saigal CS, Gore JL, Krupski TL, et al. Androgen deprivation therapy increases cardiovascular morbidity in men with prostate cancer. Cancer 2007;110:1493-500.

46. Tsai HK, D’Amico AV, Sadetsky N, Chen MH, Carroll PR. Androgen deprivation therapy for localized prostate cancer and the risk of cardiovascular mortality. J Natl Cancer Inst 2007;99:1516-24.

47. D'Amico AV, Denham JW, Crook J, et al. Influence of androgen suppression therapy for prostate cancer on the frequency and timing of fatal myocardial infarctions. J Clin Oncol 2007;25:2420-5.

48. Levine GN, D'Aamico AV, Berger P, et al. Androgen-deprivation therapy in prostate cancer and cardiovascular risk: a science advisory from the American Heart Association, American Cancer Society, and American Urological Association. Circulation 2010;121:833-40.

49. US Food and Drug Administration. FDA drug safety communication: update to ongoing safety review of GnRH agonists and notification to manufacturers of GnRH agonists to add new safety information to labeling regarding increased risk of diabetes and certain cardiovascular diseases. Available at: https://www.fda.gov/drugs/drug-safety-and-availability/fda-drug-safety-communication-update-ongoing-safety-reviewgnrh-agonists-and-notification. Accessed February 10, 2021.

50. Alibhai SMH, Duong-Hua M, Sutradhar R, et al. Impact of androgen deprivation therapy on cardiovascular disease and diabetes. J Clin Oncol 2009;27:3452-8.

51. Haque R, Ulcickasyood M, Xu X, et al. Cardiovascular disease risk and androgen deprivation therapy in patients with localised prostate cancer: a prospective cohort study. Brit J Cancer 2017;117:1233-40.

52. Nanda A, Chen MH, Braccioforte MH, Moran BJ, D’Amico AV. Hormonal therapy use for prostate cancer and mortality in men with coronary artery disease-induced congestive heart failure or myocardial infarction. JAMA 2009;302:866-73.

53. Keating NL, O'Malley AJ, Freedland SJ, Smith MR. Does comorbidity influence the risk of myocardial infarction or diabetes during androgen-deprivation therapy for prostate cancer? Eur Urol 2013;64:159-66.

54. Carneiro A, Sasse AD, Wagner AA, et al. Cardiovascular events associated with androgen deprivation therapy in patients with prostate cancer: a systematic review and meta-analysis. World J Urol 2015;33:1281-9.

55. Nguyen PL, Je Y, Schutz FAB, et al. Association of androgen deprivation therapy with cardiovascular death in patients with prostate cancer: a meta-analysis of randomized trials. JAMA 2011;306:2359-66.

56. Abufaraj M, Iwata T, Kimura S, et al. Differential impact of gonadotropin-releasing hormone antagonist versus agonist on clinical safety and oncologic outcomes on patients with metastatic prostate cancer: a metaanalysis of randomized controlled trials. Eur Urol 2021;79:44-53.

57. Zareba P, Duivenvoorden W, Leong DP, Pinthus JH. Androgen deprivation therapy and cardiovascular disease: What is the linking mechanism? Ther Adv Urol 2016;8:118-29. 
58. Melloni C, Slovin SF, Blemings A, et al. Cardiovascular safety of degarelix versus leuprolide for advanced prostate cancer. JACC: CardioOncology 2020;2:70-81.

59. Charbit B, Christin-Maitre S, Démolis JL, et al. Effects of testosterone on ventricular repolarization in hypogonadic men. Am J Cardiol 2009;103:887-90.

60. Nielsen JB, Graff C, Pietersen A, et al. J-shaped association between QTc interval duration and the risk of atrial fibrillation: results from the Copenhagen ECG study. J Am Coll Cardiol 2013;61:2557-64.

61. Jones RD, English KM, Pugh PJ, et al. Pulmonary vasodilatory action of testosterone: evidence of a calcium antagonistic action. J Cardiovasc Pharmacol 2002;39:814-23.

62. Cairrão E, Álvarez E, Santos-Silva AJ, Verde I. Potassium channels are involved in testosterone-induced vasorelaxation of human umbilical artery. Naunyn-Schmiedeberg's Arch Pharmacol 2008;376:375-83.

63. Golden KL, Marsh JD, Jiang Y, Moulden J. Acute actions of testosterone on contractile function of isolated rat ventricular myocytes. Eur J Endocrinol 2005;152:479-83.

64. Ceballos G, Figueroa L, Rubio I, et al. Acute and nongenomic effects of testosterone on isolated and perfused rat heart. J Cardiovasc Pharmacol 1999;33:691-7.

65. Nettleship JE, Jones TH, Channer KS, Jones RD. Physiological testosterone replacement therapy attenuates fatty streak formation and improves high-density lipoprotein cholesterol in the $\mathrm{Tfm}$ mouse: an effect that is independent of the classic androgen receptor. Circulation 2007; 116:2427-34.

66. Mukherjee TK, Dinh H, Chaudhuri G, Nathan L. Testosterone attenuates expression of vascular cell adhesion molecule- 1 by conversion to estradiol by aromatase in endothelial cells: implications in atherosclerosis. Proc Natl Acad Sci U S A 2002;99:4055-60.

67. Mäkinen J, Järvisalo MJ, Pöllänen P, et al. Increased carotid atherosclerosis in andropausal middle-aged men. J Am Coll Cardiol 2005;45:1603-8.

68. Mathur A, Malkin C, Saeed B, et al. Long-term benefits of testosterone replacement therapy on angina threshold and atheroma in men. Eur J Endocrinol 2009;161:443-9.

69. Zitzmann M. Testosterone deficiency, insulin resistance and the metabolic syndrome. Nat Rev Endocrinol 2009;5:673-81.

70. Th Jones, Kelly D. Randomized controlled trials—mechanistic studies of testosterone and the cardiovascular system. Asian J Androl $2018 ; 20: 120-30$

71. Oskui PM, French WJ, Herring MJ, et al. Testosterone and the cardiovascular system: a comprehensive review of the clinical literature. J Am Heart Assoc 2013;2:e000272.

72. Ajayi AAL, Halushka PV. Castration reduces platelet thromboxane A2 receptor density and aggregability. QJM Monthly J Assoc Phys 2005;98:349-56.

73. Webb CM, Elkington AG, Kraidly MM, et al. Effects of oral testosterone treatment on myocardial perfusion and vascular function in men with low plasma testosterone and coronary heart disease. Am J Cardiol 2008;101:618-24.

74. Shahwan MM, Spathis GS, Fry DE, Wood PJ, Marks V. Differences in pituitary and testicular function between diabetic patients on insulin and oral anti-diabetic agents. Diabetologia 1978;15:13-7.

75. Corona G, Monami M, Rastrelli G, et al. Type 2 diabetes mellitus and testosterone: a meta-analysis study. Int J Androl 2011;34:528-40.
76. Heufelder AE, Saad F, Bunck MC, Gooren L. Fifty-two-week treatment with diet and exercise plus transdermal testosterone reverses the metabolic syndrome and improves glycemic control in men with newly diagnosed type 2 diabetes and subnormal plasma testosterone. J Androl 2009;30:726-33.

77. Inaba M, Otani Y, Nishimura K, et al. Marked hyperglycemia after androgen-deprivation therapy for prostate cancer and usefulness of pioglitazone for its treatment. Metab: Clin Exper 2005;54:55-9.

78. Dowman JK, Hopkins LJ, Reynolds GM, et al. Loss of $5 \alpha$-reductase type 1 accelerates the development of hepatic steatosis but protects against hepatocellular carcinoma in male mice. Endocrinology 2013;154:4536-47.

79. Paik SG, Michelis MA, Kim YT, Shin S. Induction of insulin-dependent diabetes by streptozotocin. Inhibition by estrogens and potentiation by androgens. Diabetes 1982;31:724-9.

80. Palomar-Morales M, Morimoto S, Mendoza-Rodríguez CA, Cerbón MA. The protective effect of testosterone on streptozotocin-induced apoptosis in $\beta$ cells is sex specific. Pancreas 2010;39:193-200.

81. Ballester J. Tungstate treatment improves leydig cell function in streptozotocin-diabetic rats. J Androl 2005;26:706-15.

82. Pitteloud N, Hardin M, Dwyer AA, et al. Increasing insulin resistance is associated with a decrease in Leydig cell testosterone secretion in men. J Clin Endocrinol Metab 2005;90:2636-41.

83. Singh R, Artaza JN, Taylor WE, Gonzalez-Cadavid NF, Bhasin S Androgens stimulate myogenic differentiation and inhibit adipogenesis in $\mathrm{C} 3 \mathrm{H} 10 \mathrm{~T} 1 / 2$ pluripotent cells through an androgen receptor-mediated pathway. Endocrinology 2003;144:5081-8.

84. Singh R, Artaza JN, Taylor WE, et al. Testosterone inhibits adipogenic differentiation in 3T3-L1 cells: nuclear translocation of androgen receptor complex with $\beta$-catenin and T-cell factor 4 may bypass canonical Wnt signaling to down-regulate adipogenic transcription factors. Endocrinology 2006;147:141-54.

85. Gupta V, Bhasin S, Guo W, et al. Effects of dihydrotestosterone on differentiation and proliferation of human mesenchymal stem cells and preadipocytes. Molec CellEndocrinol 2008;296:32-40.

86. Caprio M, Isidori AM, Carta AR, et al. Expression of functional leptin receptors in rodent Leydig cells. Endocrinology 1999;140:4939-47.

87. Lorigo M, Mariana M, Lemos MC, Cairrao E. Vascular mechanisms of testosterone: the non-genomic point of view. J Steroid Biochem Molec Biol 2020;196:105496.

88. Kapoor D, Clarke S, Stanworth R, Channer KS, Jones TH. The effect of testosterone replacement theraphy on adipocytokines and C-reactive protein in hypogonadal men with type 2 diabetes. Eur J Endocrinol 2007; 156:595-602.

89. Crisostomo PR, Wang M, Wairiuko GM, Morrell ED, Meldrum DR Brief exposure to exogenous testosterone increases death signaling and adversely affects myocardial function after ischemia. Am J PhysiolRegul Integr ComparPhysiol 2006;290:R1168-74.

90. Rettew JA, Huet-Hudson YM, Marriott I. Testosterone reduces macrophage expression in the mouse of toll-like receptor 4, a trigger for inflammation and innate immunity. Biol Reprod 2008;78:432-7.

91. Malkin CJ, Pugh PJ, Jones RD, et al. The effect of testosterone replacement on endogenous inflammatory cytokines and lipid profiles in hypogonadal men. J Clin Endocrinol Metab 2004;89:3313-8.

92. Hong CY, Park JH, Ahn RS, et al. Molecular mechanism of suppression of testicular steroidogenesis by proinflammatory cytokine tumor necrosis factor alpha. Molec Cell Biol 2004;24:2593-604. 
93. Rennie K, McCarthy N, Yazdgerdi S, Marmot M, Brunner E. Association of the metabolic syndrome with both vigorous and moderate physical activity. Int J Epidemiol 2003;32:600-6.

94. Kriska AM. Physical activity, obesity, and the incidence of type 2 diabetes in a high-risk population. Am J Epidemiol 2003;158:669-75.

95. Lahti-Koski M, Pietinen P, Heliövaara M, Vartiainen E. Associations of body mass index and obesity with physical activity, food choices, alcohol intake, and smoking in the 1982-1997 FINRISK Studies. Am J Clin Nutr 2002;75:809-17.

96. Hu G, Barengo NC, Tuomilehto J, et al. Relationship of physical activity and body mass index to the risk of hypertension: a prospective study in Finland. Hypertension 2004;43:25-30.

97. Young DR, Hivert MF, Alhassan S, et al. Sedentary behavior and cardiovascular morbidity and mortality: a science advisory from the American Heart Association. Circulation 2016;134:e262-79.

98. Martin BJ, Arena R, Haykowsky M, et al. Cardiovascular fitness and mortality after contemporary cardiac rehabilitation. Mayo Clin Proc 2013;88:455-63.

99. Bhasin S, Storer TW, Berman N, et al. The effects of supraphysiologic doses of testosterone on muscle size and strength in normal men. N Engl J Med 1996;335:1-7.
100. Shiels MS, Rohrmann S, Menke A, et al. Association of cigarette smoking, alcohol consumption, and physical activity with sex steroid hormone levels in US men. Cancer Causes Control 2009;20:877-86.

101. Muller M, den Tonkelaar I, Thijssen JHH, Grobbee DE, van der Schouw YT. Endogenous sex hormones in men aged 40-80 years. Eur J Endocrinol 2003;149:583-9.

102. Camacho EM, Huhtaniemi IT, O’Neill TW, et al. Age-associated changes in hypothalamic-pituitary-testicular function in middle-aged and older men are modified by weight change and lifestyle factors: longitudinal results from the European Male Ageing Study. Eur J Endocrinol 2013;168:445-55.

103. Kumagai H, Zempo-Miyaki A, Yoshikawa T, et al. Increased physical activity has a greater effect than reduced energy intake on lifestyle modification-induced increases in testosterone. J Clin Biochem Nutr 2016;58:84-9.

104. Kumagai H, Yoshikawa T, Zempo-Miyaki A, et al. Vigorous physical activity is associated with regular aerobic exercise-induced increased serum testosterone levels in overweight/obese men. Horm Metabl Res 2018;50:73-9.

105. Kraemer WJ, Häkkinen K, Newton RU, et al. Acute hormonal responses to heavy resistance exercise in younger and older men. Eur J Appl Physiol Occup Physiol 1998;77:206-11. 